\title{
UNIVERSALISMO VS. RELATIVISMO CULTURAL: UNA BATALLA POR LA DEFINICIÓN DE LOS DERECHOS HUMANOS Y LA DISCRIMINACIÓN
}

\author{
Rita Boco ${ }^{1}$ \\ Gisela Bulanikia ${ }^{2}$
}

\begin{abstract}
RESUMEN
A través de un recorrido histórico, rastreamos la construcción del concepto Derechos Humanos y el contexto socio histórico en que se produjo, abordándolo a través de la dicotomía relativismo cultural/universalismo y de las ideologías que los guían. La desigualdad y la vulnerabilidad de amplios sectores sociales en el contexto global da lugar a la construcción de estereotipos discriminatorios que se apoyan en diferencias manifestadas en la condición económica y en la cultura. Profundizar en las tensiones entre lo particular/universal cuestiona los significados que fueron impuestos por el sector hegemónico y las clasificaciones que produce.
\end{abstract}

Palabras clave: Derechos humanos. Discriminación. Relativismo cultural. Universalismo. Globalización. Ideología.

\footnotetext{
${ }^{1}$ Dpto. Socio-antropología, Docente Auxiliar Escuela de Nutrición, Facultad de Medicina Universidad de Buenos Aires, Titular Cátedra Sociología, Carrera Lic. Nutrición, Universidad. ISALUD. Correo eletrónico: boco_rita@hotmail.com

${ }^{2}$ Profesora Adjunta, Cátedra Sociología, Carrera Lic. Nutrición, Universidad ISALUD. Correo eletrónico: gisel@ciudad.com.ar
} 


\title{
UNIVERSALISM VS. CULTURAL RELATIVISM: A BATTLE FOR THE DEFINITION OF HUMAN RIGHTS AND DISCRIMINATION
}

\begin{abstract}
Through a historical journey, we track the construction of the concept of Human Rights and socio-historical context in which it occurred, approaching it through the dichotomy of cultural relativism / universalism and the philosophies that guide them. Inequality and social vulnerability of large sectors in the global context leads to the construction of discriminatory stereotypes that are based on differences manifested in the economic condition and culture. Deepening the tension between the particular / universal questions the meanings that were imposed by the dominant sector and the classifications it produces.
\end{abstract} Keywords: Human rights. Discrimination. Cultural relativism. Universalism. Globalization. Ideology.

\section{INTRODUCCIÓN}

$\mathrm{L}$

a preocupación por los derechos humanos forma parte del reconocimiento de que estamos ante un mundo interdependiente. Este concepto, pese a su origen reciente (1948), ha ganado significación global. Los derechos humanos forman parte de múltiples perspectivas y puntos de vista, a veces conflictivos, ya que se han universalizado como valores reinterpretados, contextualizados, adaptados y renegociados de diferente manera en cada rincón del planeta.

A tales diferencias se refieren los relativistas cuando argumentan que los derechos humanos corporizan en sí mismos prejuicios y son, por lo tanto, un "constructo etnocéntrico" con aplicabilidad limitada. Para los relativistas, que sostienen que existe una amplia diversidad de sistemas morales y de justicia no occidentales, los derechos humanos entran en conflicto con los diversos sistemas culturales. Por lo tanto, se argumenta que cualquier teoría viable sobre los derechos humanos debería tomar en cuenta esta diversidad. Mientras que los defensores de los derechos humanos, a quienes llamaremos universalistas, argumentan que éstos son derechos inherentes a todas las personas, más allá de la cultura, la raza, el sexo, la religión, el género. Estos derechos están presumiblemente fundados en la naturaleza humana, una concepción occidental en sí misma, y serían universales e inalienables. Para tener derechos humanos, según esta perspectiva, basta la condición ser humano. 
Nuestra intención es hacer visible otras aristas de los derechos humanos, para reconocerlos como más cercanos a nuestras vidas. La propuesta es entender las acciones y prácticas que definimos como derechos que cobran sentido porque su significado surge de relaciones y eventos sociales, históricos, políticos, económicos y culturales que les dan forma y que a su vez son transformados por las prácticas sociales.

El concepto derechos humanos encierra en si qué es vida humana, es decir, qué es lo que definimos como prácticas y acciones que hacen posible y garantizan la existencia de vida humana. La defensa de los derechos humanos debe ponernos en alerta sobre los efectos de la economía política, el capitalismo transnacional, la ubicuidad del poder y las desigualdades sociales.

\section{Recorrido y Memoria de los Derechos Humanos}

Un discurso no viene al mundo en una inocente soledad sino que se construye a través de un ya dicho en relación al cual toma posición en un contexto determinado. Se empieza a hablar de derechos humanos a partir del pensamiento racional del Siglo de las Luces. Son los filósofos del siglo XVII los que apoyados en nociones comparables a las de los derechos humanos se proponen desafiar el Absolutismo Político. Este sistema de gobierno representaba un estado de transición entre el feudalismo y el capitalismo de las monarquías de Europa occidental. El absolutismo, como régimen otorgaba al rey, imbuido de poder divino, la posesión de hecho y de derecho de todos los atributos de la soberanía: hacer las leyes, administrar la justicia, recaudar impuestos, disponer del uso de la fuerza a través de los ejércitos. Frente a esta concepción de la sociedad surgen ideas como las de Locke, Montesquieu y Rousseau que plantean que los individuos que habitan un territorio determinado son ciudadanos y no súbditos. El tránsito de la sociedad tradicional a la sociedad moderna está marcado por el cambio del vínculo social de los individuos. Mientras en la primera éste era entendido como "natural", en la sociedad moderna se convertirá en voluntario y artificial basándose en la idea de contrato. De la mano de estas ideas con la Revolución Francesa se hace la Declaración de Derechos del Hombre abriendo el camino para la Declaración de los Derechos Humanos.

La premisa básica de los derechos humanos será, desde entonces, que cada ser humano tiene derechos inalienables que no pueden ser negados por ningún régimen, cualquiera sea su justificación. Por primera vez en la historia se utiliza 
el lenguaje del derecho para expresar normas morales universales. A partir de ese momento denominamos derechos "naturales" al derecho a la vida y la libertad que supuestamente todos disfrutamos.

En Inglaterra, en un proceso similar al que ocurría en Francia, surgió el primer documento que estableció limitaciones de naturaleza jurídica al ejercicio del poder del Estado frente a sus súbditos: nos referimos la Carta Magna de 1215, la cual junto a el Hábeas Corpus de 1679 y la Bill of Rights de 1689 pueden considerarse como precursores de las modernas declaraciones de derechos.

Antes de la Segunda Guerra Mundial, la consideración internacional sobre los Derechos Humanos estaba limitada a documentos nacionales: la Carta Magna, declaración de los Derechos del Hombre y del Ciudadano, y las constituciones nacionales.

No obstante, la aparición de los derechos humanos en plena escena deberá esperar a las transformaciones políticas y económicas de 1948 que la hacen no sólo posible sino necesaria. Surge un fuerte deseo de establecer estándares internacionales para prevenir la clase de atrocidades atestiguadas en esa guerra. Así, en 1945, delegados de varios países se encontraron en San Francisco para diagramar la carta de las Naciones Unidas. Este grupo creó la Comisión de los Derechos Humanos, con el fin de establecer estándares internacionales de dignidad y el 10 de diciembre de 1948 se adoptó la Declaración Universal de los Derechos Humanos, con abstención del bloque comunista, de Sudáfrica y Arabia Saudita.

Por los hechos que se producen durante la Segunda Guerra Mundial, definidos como delitos de lesa humanidad, se procura imponer los Derechos Humanos como una moral universal. Con la Declaración Universal de los Derechos Humanos los individuos se volvieron sujetos del derecho internacional. Hasta ese momento, solo existían leyes concernientes a la responsabilidad de los Estados por daños a extranjeros como reparaciones en caso de contienda bélica. La ficción era que el Estado al que pertenecía el extranjero era el sujeto del daño. Históricamente, como un Estado trataba a sus ciudadanos dentro de su territorio era un asunto exclusivamente interno e implícito en el concepto de soberanía territorial. Tal declaración fue el primer intento de establecer estándares universales para todas las personas de todas las naciones, adquiriendo status judicial significativo en el mundo. Sin embargo, durante años la mayoría de países adhirieron solo teóricamente a la obligación de respetar los derechos humanos. 
De acuerdo con los relativistas, los derechos humanos son inseparables de la mentalidad del Siglo de las Luces y no dejan de ser el producto de una sociedad particular en un momento dado: Europa pos-guerra y una construcción occidental con aplicabilidad limitada.

La noción contemporánea de derechos humanos los presenta como resultado del derecho natural que tiene su fundamento en la naturaleza humana y al que Locke categorizó como inalienable. Sin embargo, el derecho natural se proclamaba dentro de un universo de valores compartidos, razón por la cual no fueron cuestionados; mientras que los derechos humanos hoy se proponen como universales en un mundo multicultural.

Los defensores de los Derechos Humanos proponen que, pese a su origen occidental, la noción es universalmente aplicable o que es posible forjar un consenso a través del diálogo intercultural. Mientras los que se oponen argumentan que la extraordinaria diversidad existente en sistemas morales impide cualquier clase de acuerdo con aplicabilidad universal.

Los que se apoyan en la teoría Kantiana para fundamentar la universalización de los derechos del hombre asumen la existencia de un solo patrón de razonamiento universal. Este se construye a partir de considerar al hombre como un ser dotado de inteligencia que selecciona y ordena lo que de otro modo sería caótico. El pensamiento kantiano afirma la necesidad de la sensibilidad y el entendimiento por igual para que exista el conocimiento. El entendimiento contribuye a la tarea de sistematización de la diversidad de la experiencia a través de categorías o nociones de entendimiento. De esta manera, se presume que el proceso de razonamiento abstracto genera un resultado universal, más allá de las diferencias culturales. Lo que subyace a esta presunción de universalidad es la creencia de que todos pensamos de la misma manera. Aunque es posible que individuos de una misma cultura estén de acuerdo con los mismos principios, la premisa de que los individuos puedan negociar principios en ausencia de cultura, por el solo hecho de la existencia de un único razonamiento abstracto, es obviamente ficcional. En realidad, es sólo dentro de un universo de valores compartidos que la presunción de universalidad no encuentra dificultades.

El problema surge a raíz de que algunos de los derechos de la Declaración Universal no son compatibles con la diversidad de sistemas de valores del mundo, razón por la cual la Declaración Universal aparece como la imposición de un sistema de valores extranjeros a las tradiciones no occidentales. Desde el punto de 
vista universalista, las objeciones de los relativistas pueden ser (y han sido) usadas para la conveniencia o excusa de aquellos Estados que controlan las políticas de desarrollo y se posicionan a favor de un poder político que justifica las violaciones sistemáticas a los derechos individuales.

\section{UNA AGENDA OCULTA}

Para entender la agenda oculta del universalismo tenemos que volver a la historia del liberalismo político y su expresión en la doctrina moderna de los derechos humanos. Vemos entonces como las ideas de Locke no pueden ser separadas de las de Adam Smith. Junto con la idea central de una definición occidental de las libertades fundamentales surge el derecho a la propiedad privada. Así, el liberalismo económico y el liberalismo político son hermanos siameses en la filosofía occidental.

El derecho a la libertad del voto es la piedra fundamental de este pensamiento, en el que la libertad de elección constituye al individualismo como su rasgo característico. El individuo, desde esta óptica, se convierte en tal, a través del ejercicio de esa libertad asociada con la libertad de elección para el consumo. Así, se entiende parte de la virulencia de occidente en la defensa de los temas de libertades fundamentales marcando la relación inseparable entre los derechos humanos y la globalización de la economía. El liberalismo político ha sustentado la economía liberal que la ha legitimado. Desde este punto de vista, los derechos humanos contribuyen a constituir ciudadanos poseedores de las características que los hacen aptos para una economía de mercado.

Desde el Consenso de Washington, la expansión del neoliberalismo como ideología, ha enmascarado objetivos políticos detrás de un discurso pseudo científico.

\section{LA DIFERENCIA Y LA DISCRIMINACIÓN}

Como analizaba Barth: los límites étnicos de la diversidad cultural son categorías que no dependen de la ausencia de movilidad, contacto o información. Ellos implican procesos sociales de inclusión o exclusión sostenidos por los propios actores sociales y "generalmente son el fundamento mismo sobre el cual están construidos sistemas sociales que las contienen" y "la interacción no conduce a su liquidación como consecuencia del cambio y la aculturación; las 
diferencias culturales pueden persistir a pesar del contacto interétnico y de la interdependencia." (BARTH, 1976, p.10).

El consenso en la década de 1960 acerca de la definición de grupo étnico incluía cuatro elementos referidos a la continuidad biológica, la permanencia de valores culturales, comunicación (lenguaje), identificación y diferenciación. Estas características enumeradas nos permiten una mirada crítica que se traducen como diferencia racial, diferencia cultural, separatismo social, barreras de lenguaje, enemistad organizada.

El énfasis de la explicación teórica de Barth radica en que la característica de auto adscripción y adscripción por los otros es fundamental para resolver los cuestionamientos centrados en la ubicación geográfica y en la permanencia de formas culturales. Así, Barth sostiene que la continuidad de un grupo étnico está dada por la conservación de un límite, y a pesar de que las características culturales de los integrantes del grupo, la forma de organizarse e incluso las formas culturales que señalan esa frontera pueden cambiar, el grupo permanece mientras exista la diferenciación entre nosotros y los otros.

Esta breve recapitulación sobre las consideraciones teóricas desarrolladas por Barth nos sirve para introducir un cuestionamiento acerca de soluciones políticas alcanzadas en el siglo XX, que se basaron en la demarcación de límites (fronteras) que no consideraron la existencia de límites culturales. Así vimos resurgir conflictos con componentes étnicos en lugares donde se creían solucionados, como los tratados firmados al finalizar las dos guerras mundiales.

Autores como Wieviorka (1992, p. 101-104) llamaron la atención sobre un uso ideológico de la diferencia para legitimizar la discriminación, sustituyendo el viejo racismo biológico por la naturalización de particularidades culturales. Hoy por hoy, los rasgos culturales valorados como negativos son los que constituyen al grupo que los detenta en diferente, creando la autojustificación de su ubicación en los estratos más bajos de una determinada jerarquía moral. Así se justifica también su instalación estructural en lugares de alta vulnerabilidad social, sin derechos o con menos derechos que el resto de la población. En definitiva, provoca el mismo resultado de deshumanización sobre aquellos a quienes se valora negativamente desde lo cultural, permitiendo accionar sobre ellos con diferentes grados de violencia.

Vemos que las guerras civiles, los genocidios, los movimientos guerrilleros independentistas, el resurgimiento de lealtades ancestrales perpetúan la miseria 
y los grandes negocios, más allá de las formas que adopten los gobiernos que se quieren imponer como salvadores y defensores de sus derechos. Podemos hacer saltar nuestra mirada de un continente a otro y en todos encontrar lastimosas experiencias. Lo que encontramos es la transformación de la imposición de la homogeneidad cultural - típicas de la época colonial y el imperialismo del siglo XIX - hacia una valorización política de la diversidad cultural, que tiene como efecto despolitizar la economía. (Díaz Polanco, 2006:10).

\section{IDEOLOGÍAS Y FACTORES SOCIO-ECONÓMICOS EN PUGNA}

Debemos aclarar que así como los derechos humanos universales pueden disfrazar una agenda oculta, lo mismo ocurre con aquellos que utilizan el discurso relativista. Ninguno de ellos está libre de ellas y en el caso de una mirada relativista puede considerarse que una desmesurada consideración por la diferencia cultural enmascara el escaso interés por desentrañar las relaciones de poder que existen en cada sociedad. Para sustentar estas posturas surgen estrategias discursivas para argumentar y justificar la exclusión.

Como señala Adam Kuper, (2001, p. 75) "la cultura se utiliza como eufemismo políticamente correcto de raza" y el racismo cultural naturaliza una diferencia que se considera que es cultural, pero está instalada más allá de la voluntad personal de quienes la detentan. Por lo tanto, las diferencias culturales se consideran inconmensurables, fijas y al igual que el racismo llevan a la conclusión de que son diferencias irrevocables.

Gellner mostraba su preocupación por la diferencia y expresaba que "El rasgo verdaderamente esencial de lo que llamamos la sociedad humana es su asombrosa diversidad" (GELLNER, 1997, p. 17). La diversidad cultural y sus desafíos nos ubican en la actualidad en un escenario donde "vivimos más y más en medio de un enorme collage", donde las culturas se ponen en contacto, confrontan, friccionan, se tensionan, siendo que éstas pueden aparecer como la causa de los conflictos sociales o como su justificación. Ni el relativismo cultural, ni el universalismo escapan a manipulaciones políticas.

Los intentos por definir los derechos humanos han llevado a distinguir los derechos civiles y políticos de los derechos económicos y sociales, desde 1966, año en que se firmaron el Pacto Internacional de Derechos Civiles y Políticos y el de los 
Derechos Económicos, Sociales, y Culturales. Estos dos tipos de derechos emergen de la competencia de las tradiciones filosóficas marxista y liberal.

A lo largo de la década 1990 las transformaciones del mundo globalizado se reflejan en los cambios de concepciones en el campo de los derechos humanos. La Declaración de Viena (1993) reafirmó la indivisibilidad, la universalidad, la interrelación y la interdependencia de los derechos humanos, el derecho al desarrollo y la relación necesaria entre derechos humanos, democracia y desarrollo como condiciones de vida para todas las personas humanas. (Declaração e Programa de Ação de Viena).

A partir de la Declaración de Estambul (1996) se nota un retroceso en los espacios que se habían creado para monitoreo y desarrollo a partir de Viena. El resultado es que la década de 1990 muestra una gran visibilidad de las cuestiones sobre derechos humanos: se enfatiza la relación democracia y participación, así como la interacción entre estado, organizaciones de la sociedad civil e individuo. La contracara de esto es una protección selectiva de los derechos humanos en la esfera internacional, originada en los intereses geopolíticos de las potencias mundiales junto con los cambios y transformaciones en las alianzas de los movimientos fundamentalistas (KOERNER, 2002, p. 88-89).

El Banco Interamericano de Desarrollo (1998, p. 2) reconoció que en condiciones de vida democrática la provisión y financiamiento de la educación y la salud, abandonada a la libre competencia de los mercados, no provocaba una respuesta efectiva a la demanda; a la vez que limitaba el acceso a estos servicios de los sectores más pobres.

De esta manera, el compromiso con los derechos humanos no necesariamente termina con la discusión planteada entre relativismo y universalismo. Esta se traslada a otra área de conflicto, no menos áspera: la economía política. Enfocados en la inequidad económica, los economistas políticos proponen que los derechos económicos deberían tener absoluta prioridad sobre el resto de los derechos, mientras que los occidentales del primer mundo hacen hincapié en los derechos civiles y políticos. Para ellos estos derechos deben tutelar ante todo la esfera de la libertad individual contra el excesivo poder del Estado.

Decimos que la discusión universalista-relativista también se traslada a las cuestiones de la economía política porque la noción de necesidad está implícita en el concepto de derecho, y en especial de aquellos que involucran a la orbita de 
lo económico y social. Es decir, ¿qué necesidades deben ser atendidas y satisfechas con el rango de derecho adquirido?

Desde la óptica de lo cultural se reconoce que existen mediaciones simbólicas que transforman una carencia específica en necesidades sociales. A partir de ellas, los distintos grupos humanos realizan la elaboración cultural de las necesidades, que a la vez le dan sentido al mundo (HERSKOVITS, 1954, p.13).

A partir del reconocimiento de una unidad de identidad junto a las diferencias de procesos sociales que resultan en diferentes modos de vida, es que sostenemos que es posible establecer una dinámica entre valores universales y particulares. No desconocer que se hacen usos políticos de las diferencias evita que éstas terminen convertidas en excusas al servicio de métodos de exclusión y jerarquización. Reconocemos que las particularidades también encierran relaciones de poder y que es desentrañando este tipo de relaciones donde se debe iniciar el camino para alcanzar el consenso.

Creemos que un acercamiento político-económico a los derechos humanos es útil para dar luz sobre la estructura que sostiene la maquinaria de abusos. Cuando no se toman en cuenta las consecuencias desastrosas de la pobreza sino que se las ignora o consideran como un simple factor sin valor sobre la libertad se está colaborando para sostener la ignorancia pública. Por lo tanto, se crea indiferencia sobre un tema más amplio acerca de cómo la pobreza cumple el rol de minar las libertades individuales en todo el mundo. De esta manera, las representaciones de las elites pueden coadyuvar a perpetuar áreas de silencio sobre las causas últimas de opresión, aun conociéndose la condición de los oprimidos.

En nuestro país, Argentina, la falta de poder económico (es decir el poder de autodeterminación económico para vivir con dignidad) sienta las bases para que los oprimidos económicamente sean privados a su vez de libertades civiles. El clientelismo político entendido como un intercambio de favores por votos es una realidad conocida por nosotros. Estos favores implican dinero, alimentos, materiales para construcción y calzado, también incluyen la llamada "política de tierras", es decir, arreglos discrecionales respecto a la posesión de lotes o cesión de tierras fiscales (BOCO y BULANIKIAN 2005, p.248-249). Esta breve descripción de los favores que se intercambian descubre las carencias que deberían ser garantizadas como derechos sociales y económicos.

Nuestro acercamiento pretende sostener los fundamentos de los derechos civiles y políticos, al mismo tiempo que nos preguntamos por las condiciones 
materiales de desarrollo. Este proceso debería dar como resultado la alteración fundamental de la noción originaria. Así, el principio de respeto igualitario no quedaría definido de una vez y para siempre. Por el contrario, queda en entredicho las originales formas de pensar los derechos humanos y la relación entre derechos civiles y económicos en el contexto de creciente empobrecimiento de amplios sectores sociales. Con este fin pensamos redefinir los derechos económicos en términos de libertad, como autonomía personal o ausencia de restricciones externas sobre las individuales, libertad de la gente a "elegir vivir como ellos lo deseen".

La buena salud y educación son pilares que construyen estándares de vida que amplían nuestra libertad, no sólo porque permiten desarrollar actividades que la enfermedad, la pobreza y la ignorancia nos prohibirían, sino porque además amplían la frontera de nuestros deseos sobre la clase de vida que nos gustaría vivir.

Para que una teoría de los derechos humanos tenga valor global deberá reconocer que, muchas veces, los fundamentos morales descansan en ideologías económicas de clase que la sustentan y, por lo tanto, lo económico no puede separarse de las combinaciones sociales y políticas de la sociedad, sino que está incrustado en ellas (POLANYI, 1976, p. 155-178).

\section{LA COMPLEJIDAD DE UN ESCENARIO GLOBALIZADO: MIGRACIÓN Y DISCRIMINACIÓN}

En el debate surgido sobre la instauración a nivel global de los Derechos Humanos la comprensión del contexto global se vuelve crucial. A partir de la independencia de las últimas colonias europeas, a mediados del siglo XX, y las secuelas independentistas, la ficción de compartimentos culturales estancos se ha derrumbado. La noción de una cultura auténtica como universo autónomo e internamente coherente ya no es sostenible, excepto quizá como una ficción útil 0 distorsión reveladora.

La globalización, tal como la describió Octavio Ianni (1998, p.6, traducción nuestra), aparece como "un proceso histórico social de vastas proporciones, que conmueve los marcos de referencia sociales y mentales de los individuos y colectividades. (...) Los territorios y las fronteras, los regímenes políticos y los estilos de vida, las culturas y las civilizaciones parecen mezclarse, tensionarse, y dinamizarse en otros modos, direcciones y posibilidades." En el campo de la 
economía, la globalización se caracterizó por la instauración a nivel planetario del modelo neoliberal.

El surgimiento del capitalismo en Europa Occidental estuvo acompañado y condicionado por las aperturas comerciales con economías de otras regiones del mundo, tanto como por la extensión territorial de las unidades políticas que lo originaron. Esta expansión, "mundializada", sólo implicaba la expansión geográfica de las actividades económicas mas allá de las fronteras nacionales (WORSLEY, 1966, p. 17). En esta etapa de la globalización, además de la extensión geográfica, se acentuó el grado de integración funcional (expresado a través de la fragmentación y deslocalización de las diferentes etapas de la producción distribución y consumo) entre economías dispersas.

Los principios del Consenso de Washington -cuya primera formulación data de 1990 - fueron considerados fines en sí mismos y aplicados como dogma. Los temas sobre los cuales existiría acuerdo eran: disciplina presupuestaria; cambios en las prioridades del gasto público (de áreas menos productivas a sanidad, educación e infraestructuras); reforma fiscal encaminada a buscar bases imponibles amplias y tipos marginales moderados; liberalización financiera, especialmente de los tipos de interés; búsqueda y mantenimiento de tipos de cambio competitivos; liberalización comercial; apertura a la entrada de inversiones extranjeras directas; privatizaciones; desregulaciones; garantía de los derechos de propiedad (RODRIK, 2004, p.1).

La última década del siglo XX finalizó con un reconocimiento explícito de que los países en desarrollo se vieron bloqueados por el proteccionismo de los países desarrollados. Su aplicación se dirigió a aquellos países, como los de nuestra región, donde la pobreza y las diferencias entre los que tienen más y los más desfavorecidos ya eran importantes (RODRIK, 2004, p. 6). Pero las barreras y las políticas económicas de bloques continentales y de los organismos internacionales de crédito no desaparecieron (CHOSSOUDOVSKY, 2002, p.18).

Otro de los componentes de la globalización neoliberal se expresó en el hecho de que en este sistema la producción, transporte y ventas de bienes concretos de la economía mundial se redujo, mientras creció la compra y venta de valores o de monedas (AMIN, 2008). Según Samir Amin, la dominación de las lógicas financieras sobre las inversiones productivas es la consecuencia de la crisis de la acumulación de capital de este modelo. La fase neoliberal se nos presenta como 
un periodo dentro de la historia capitalista que dejó sin respuesta al requerimiento de equidad.

Según Chossudovsky (1998), economista canadiense: "No hay necesidad de recolonizar territorios perdidos o de enviar ejércitos invasores (aunque se sigue haciendo). (...) A fines del siglo XX la guerra financiera no reconoce fronteras territoriales para controlar los medios de producción, la fuerza laboral y los recursos naturales". Así, la globalización resultó, una máquina estratificante "que opera no tanto para abolir las diferencias sino para reordenarlas con el fin de producir nuevas fronteras, menos ligadas a los territorios que a la distribución desigual de los bienes en los mercado". (GROSSBERG apud GARCÍA CANCLINI, 2000).

Ese es el escenario global en el que estalla la burbuja financiera en Estados Unidos y Europa a fines del 2008. La economía transnacional es parte estructural de nuestro mundo actual y, tal como lo expresaba Chomsky (2000, p.184), el Senado virtual que configuraron los especuladores de los mercados financieros convirtió al mundo en un mercado. La debilidad de algunos estados, y la fuerza de otros, muestran los conflictos de esta época y es la razón de las violaciones a los Derechos Humanos de este tiempo.

Los países que lograron una situación privilegiada no lo hicieron como corolario de la aplicación de las leyes objetivas del mercado y de la competencia perfecta pregonadas por el neoliberalismo, sino, como ya lo señalara Samir Amin, debido al control exclusivo de cinco áreas fundamentales de poder en base a las cuales se imponen: a) el monopolio tecnológico, b) el control de los mercados financieros mundiales, c) el monopolio de acceso a los recursos naturales del planeta, d) el monopolio de los medios de comunicación y e) el monopolio de las armas de destrucción masiva (AMIN, 2001, p. 25).

Con la globalización cae el muro de Berlín, pero florece la xenofobia y la violencia contra los inmigrantes. En nuestro continente, los muros ya ni siquiera son invisibles sino que se han convertido en enmallados eléctricos y policías de migración que masacran abiertamente, en la frontera entre México y Estados Unidos. Como dice Renato Ortiz, "La comprensión de un mundo desterritorializado requiere de un punto de vista desterritorializado" (1997, p. 19).

La inseguridad por la desaparición de derechos adquiridos (empleo, vivienda) lleva al debilitamiento del factor de clase como aglutinador político (BOCO y BULANIKIAN, 2005, p. 258-259). Lo que se percibe es la fragilidad de una 
identidad, colectiva y personal, que se siente amenazada por la mundialización de los modos de vida y la estandarización cultural. El vacío que deja el retroceso del Estado genera ambigüedad en los grupos respecto de los elementos con que cubrir este vacío. Para salvar este abismo contradictoriamente se acentúan los valores locales, al mismo tiempo que se quieren compartir los estilos de vida y valores globales.

El atentado del 11 de septiembre de 2001 desestabilizó el respeto por la diferencia, al mismo tiempo que llevó al extremo de la inconmensurabilidad del relativismo cultural. La expresión empírica fue la nueva doctrina de seguridad nacional norteamericana, denominada Guerra Preventiva, y las restricciones en la política de inmigración de ese mismo país alimentan la existencia de un mercado de mano de obra ilegal y barata.

Chicano, espalda mojada, chilote, cholo, argie, sudaca, bolita, paragua. Estos términos, usados para nominar a inmigrantes, son de importancia no solo por las acciones que se tomarán basándose en esas definiciones, sino porque el lenguaje como depositario de las construcciones sociales sedimentadas contribuye a convertir tales términos en parte del vocabulario cotidiano, naturalizando los significados que fueron impuestos por el sector hegemónico. Dar nombre tiene, por lo tanto, importantes implicaciones políticas: cuando se formulan categorías lingüísticas se está diseñando el armamento para una batalla, cuando estas categorías son aceptadas y utilizadas se logra una victoria importante.

\section{Comentarios Finales}

El riesgo para la humanidad es el de ser atacada por la enajenación de prejuicios, útiles a los fundamentalistas de cualquier bando, tengan turbante 0 traje sastre, maten con armas, con aviones o con decisiones políticas. La necesidad de algunos sectores de encontrar un enemigo, de poner un rostro al mal, nos arrastra a criminalizar al 0tro, al que es diferente en sus creencias religiosas, en sus pautas culturales o en el color de su piel deslizándonos hacia un mundo global que, a diferencia de cómo se presentaba, está enfrentado por sus diferencias.

Un crecimiento y exacerbación de la discriminación es una amenaza que impone aplastantes cargas sobre la humanidad. Por eso, coincidimos con Lins Ribeiro cuando expresa que "un análisis de los derechos humanos en tanto discurso destinado a pensar e intervenir en las crisis contemporáneas y a clasificar 
comportamientos y colectividades (grupos socialmente diferenciados, minorías étnicas e inclusive Estados-nación) puede, potencialmente, llevarnos a develar cuáles mecanismos de re producción del poder son subsumidos por ese discurso en el presente" (LINS RIBEIR0, 2004, s/ p, versión online, traducción nuestra).

Como expresamos en párrafos anteriores debemos profundizar en las tensiones que surgen entre lo particular y lo universal, en especial como reflejo de las tensiones del ejercicio del poder. El proceso que describimos de aparición y desarrollo de la noción de derechos humanos fue contemporáneo a la colonización de África y a su reparto entre las potencias europeas emergentes en el siglo XIX (Conferencia de Berlín, 1884-1885). La trata de esclavos, que hizo florecer la economía en Europa y América y desmembró y desarticuló a las civilizaciones africanas, se cimentó sobre laideología del racismo que deshumanizó a la población africana. El impacto demográfico que desde entonces se originó adquiere sentido cuando pensamos cómo los esclavos africanos repoblaron América Central - una vez que fueron exterminados los habitantes nativos y rastreamos su presencia con diferentes grados de visibilidad en toda América.

Durante este largo proceso, el concepto de raza (universal-etnocéntrico) colocaba a la población negra como una sub-especie humana que quedaba excluida de esa nueva noción de sujeto libre y de los derechos que la condición de ciudadano le confería. La segunda mitad del siglo XX está marcada por las independencias y el último cuarto de siglo por las guerras civiles y golpes de estado en las nuevas repúblicas, seguidos de nuevos desplazamientos buscando seguridad política y económica. Podemos decir que los derechos humanos civiles y económicos-sociales son vulnerados pero entender el estado actual implica considerar el largo proceso histórico de colonización-descolonizaciónindependencias que fueron moldeando los sectores hegemónicos al interior de cada país y las disputas por la posesión, extracción y obtención de ganancias de los recursos existentes. La construcción y vigencia de los poderes hegemónicos llevan en si las paradojas y conflictos de la relación entre particularismo y universalismo.

La desigualdad y la vulnerabilidad de los desplazados respecto a los ciudadanos de los países receptores dieron y dan lugar a la construcción de estereotipos discriminatorios que se apoyan en diferencias manifestadas en el cuerpo, en la condición económica y en la cultura. Esta lógica no sólo está presente para dar cuenta de la historia africana. Tratamos la oposición entre particularismo 
y universalismo como ideologías en pugna para enfatizar las relaciones de poder a través de las clasificaciones que producen.

Es por eso que debemos tratar de comprender el contexto global antes de arrojarnos a la comodidad de dividir al mundo en buenos y malos. En el mundo de la política y el poder, no hay malos y buenos, sino intereses en disputa y seres humanos que sufren las consecuencias de estas luchas.

\section{REFERENCIAS}

AMIN, Samir. Capitalismo, imperialismo y mundialización. En: SEOANE, José y TADDEI, Emilio (comp.). Resistencias mundiales (de Seattle a Porto Alegre). Buenos Aires. CLACSO. 2001.

Debacle financiera, crisis sistémica: respuestas ilusorias, respuestas necesarias. 2008. Versión online bttp://www.mondialisation.ca/index. php?context=va\&aid=11193. Consultado en: 20-05-2010.

BARTH, Frederik (comp.). Los grupos étnicos y sus fronteras. La organización social de las diferencias culturales. Introducción., México D.F., FCE, 1976.

BID Banco Interamericano de Desarrollo. América Latina Frente a la Desigualdad. Informe de Progreso Económico y Social 1998-1999. Washington, DC, Estados Unidos: BID, 1999.

BULANIKIAN Gisela. La Casa de los Espíritus: Justicia Internacional. Cuadernos de Epistemología de Ciencias Sociales, n. 5, Buenos Aires. Ed. Filosofía y Letras. pp. 5-16, 1999.

BOC0 Rita, BULANIKIAN Gisela. El Desencanto Argentino. Revista de Ciencias Humanas, Florianópolis, n. 38, pp. 245-261, 2005.

BIDART CAMPOS et. Allí. Derechos Humanos: Corte Interamericana. Opiniones consultivas. Mendoza: Ediciones Jurídicas Cuyo, 2000.

CHIRIGUini, María Cristina. Antropología, Cuaderno1. Ciclo Básico Común, Universidad de Buenos Aires. Proyecto Editorial, 2003.

CHOMSKY, Noam. El beneficio es lo que cuenta: neoliberalismo y orden global. Barcelona: Crítica, 2000.

CHOEN, Ronald. Human Rights and Cultural Relativism: The need for a new approach. American Anthropologist, Flushing, n. 91, pp. 1014-1017, 1989. 
CHOSSUDOVSKY, Michel. Guerra financiera desata crisis económica mundial. Revista del Sur, Montevideo, n. 86, 1998. Disponible en: http://www. redtercermundo.org.uy/revista_del_sur/texto_completo.php?id=869 Consultado en: 20-05-2010.

Siglo XXI, 2002.

. Globalización de la pobreza y nuevo orden mundial. Buenos Aires:

DECLARAÇÃO E PROGRAMA DE AÇÃO DE VIENA. Disponible en: http://www.dhnet. org.br/direitos/anthist/viena/declaracao_viena.htm Consultado en: 22-05-2010.

DELGADO, Manuel. La identidad en acción. La cultura como factor discursivo de exclusión y de lucha. Eikasia: Revista de Filosofía, año III, n. 17, p. 262, 2008. Disponible en: http://revistadefilosofia.com/17-08.pdf 18-03-2010/09-07-2010.

DIAZ POLANCO, Héctor. Elogio de la diversidad: globalización, multiculturalismo y etnofagia Gedisa. México: Siglo XXI, 2006.

GARCIA CANCLINI, Néstor. Políticas culturales en tiempos de la globalización. Revista de Ciencias Sociales, Bogotá, n.005, 2000. Disponible en: http://redalyc. uaemex.mx./redalyc/src/inicio/ArtPdfRed.jsp?iCve=81500506 Consultado en: 2205-2010.

GEERTZ, Clifford. Distinguished lecture: anti anti-relativism. American Anthropologist, Washington, v. 86, n. 2, pp. 263-278, 1984. . Los usos de la diversidad. Barcelona. Paidos, 1996.

GELLNER, Ernest. Antropología política. Revoluciones en el bosque sagrado. Barcelona: Gedisa, 1997.

HERSKOVITS, Melville J. Antropología económica. México: Fondo de Cultura Económica, 1954.

IANNI, Octavio. 0 Príncipe Eletrônico. XXI Encontro Anual da ANPOCS - GT 19 - Teoria Social. Caxambú, 27 a 31 de outubro, 1998. Disponible en: www.journals. unam.mx/index.php/cuc/article/view/2033/1595

JULIANO, Dolores. Globalización e identidad cultural. Buenos Aires: Ediciones Ciccus, 1997.

KOERNER, Andrei. Ordem política e sujeito de direito no debate dos Direitos Humanos”. Lua Nova, São Paulo, n. 57, pp. 87-111, 2002.

KUPER, Adam. Cultura. Barcelona: Paidós, 2001. 
LINS RIBEIR0, Gustavo. Cultura, direitos humanos e poder. Mais além do império e dos humanos direitos. Por um universalismo heteroglóssico. En: GRIMSON, Alejandro (comp.). La cultura en las crisis latinoamericanas. Buenos Aires: CLACSO, 2004. Disponible en: http://sala.clacso.org.ar/gsdl/cgi-bin/library?e=d000-00---0grup--00-0-0--0prompt-10---4------0-11--1-es-50---20-help---00031001-1-0utfZz-8-00\&a=d\&c=grup\&cl=CL4.1\&d=HASH013fa037ad4bd43ccfc4ac b7.11\#HASH013fa037ad4bd43ccfc4acb7.11

MARTINEZ, Samuel. Indifference within Indignation: Anthropology, Human Rights and the Haitian Bracero. American Anthropologist, Washington, n. 98(1), pp. 17-24, 1996.

MEDINA, Cecilia (coord.). Curso de Entrenamiento en Derecho Internacional de los Derechos Humanos para Jueces y Abogados de Sudamérica. En: Varios Autores. Buenos Aires: Cuadernos de Análisis jurídicos, 1991.

ORTIZ, Renato. Mundialización y cultura. Buenos Aires: Alianza, 1997.

POLANYI, Karl. El Sistema Económico como Proceso Institucionalizado. En: GODELIER, Maurice (comp.). Antropología y economía. Barcelona: Anagrama, 1976.

RORTY, Richard. Objetividad, relativismo y verdad. Barcelona: Paidos, 1996.

RODRIK, Dani. Rethinking growth policies in the developing world. Luca d'Agliano Lecture, Torino, 8 de octubre. 2004. Disponible en www.law.wisc.edu/ gls/documents/institutions4.pdf. 23-05-2010.

WIEVIORKA, Michel. El espacio del racismo. Barcelona: Paidós, 1992.

WORSLEY, Peter. El tercer mundo. México: Siglo XX, 1966. 